Provided for non-commercial research and education use. Not for reproduction, distribution or commercial use.

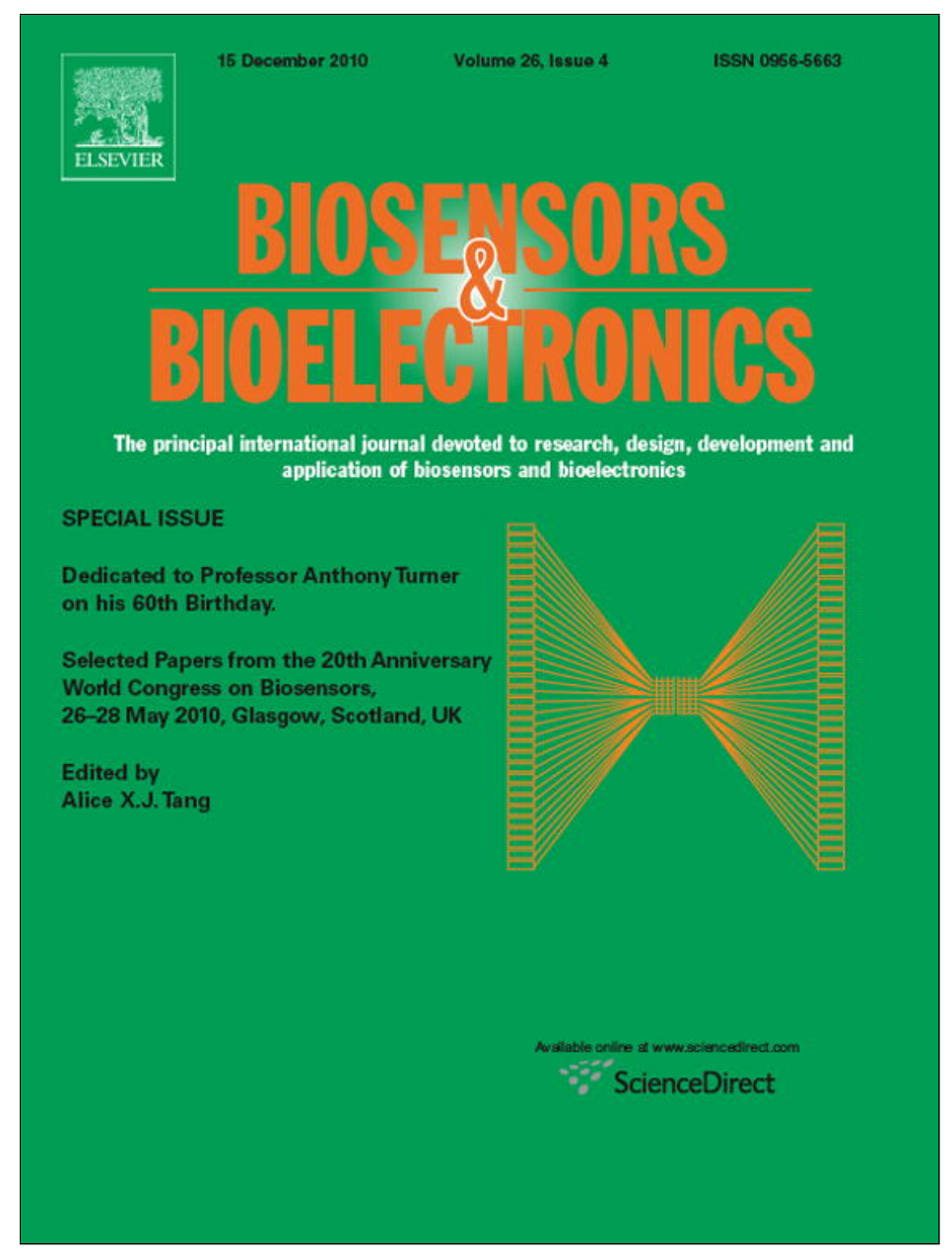

This article appeared in a journal published by Elsevier. The attached copy is furnished to the author for internal non-commercial research and education use, including for instruction at the authors institution and sharing with colleagues.

Other uses, including reproduction and distribution, or selling or licensing copies, or posting to personal, institutional or third party websites are prohibited.

In most cases authors are permitted to post their version of the article (e.g. in Word or Tex form) to their personal website or institutional repository. Authors requiring further information regarding Elsevier's archiving and manuscript policies are encouraged to visit:

http://www.elsevier.com/copyright 


\title{
Nanoliter contact angle probes tumor angiogenic ligand-receptor protein interactions
}

\author{
Giulio Olivero ${ }^{\mathrm{a}}$, Daniele Maiolo ${ }^{\mathrm{b}}$, Daria Leali ${ }^{\mathrm{b}}$, Stefania Federici ${ }^{\mathrm{a}}$, Laura E. Depero ${ }^{\mathrm{a}}$, Marco Presta ${ }^{\mathrm{b}}$, \\ Stefania Mitola ${ }^{\mathrm{b}, * *}$, Paolo Bergese ${ }^{\mathrm{a}, *}$ \\ a Chemistry for Technologies Laboratory and INSTM, University of Brescia, Via Branze, 38, 25123 Brescia, Italy \\ ${ }^{\mathrm{b}}$ Unit of General Pathology, Department of Biomedical Sciences and Biotechnology, School of Medicine, University of Brescia, Viale Europa 11, 25123, Brescia, Italy
}

\section{A R T I C L E I N F O}

\section{Article history:}

Received 14 April 2010

Received in revised form 23 July 2010

Accepted 29 July 2010

Available online 13 August 2010

\section{Keywords:}

Vascular endothelial growth factor

Contact angle

Protein-protein interactions

Angiogenesis

Surface tension

Surface-immobilized proteins

\begin{abstract}
A B S T R A C T
Any molecular recognition reaction supported by a solid phase drives a specific change of the solid-solution interfacial tension. Sessile contact angle (CA) experiments can be readily used to track this thermodynamic parameter, prompting this well-known technique to be reinvented as an alternative, easy-access and label-free way to probe and study molecular recognition events. Here we deploy this technique, renamed for this application CONAMORE (CONtact Angle MOlecular REcognition), to study the interaction of the tumor-derived pro-angiogenic vascular endothelial growth factor-A (VEGF-A) with the extracellular domain of its receptor VEGFR2. We show that CONAMORE recognizes the high affinity binding of VEGF-A at nanomolar concentrations to surface-immobilized VEGFR2 regardless of the presence of a ten-fold excess of a non-specific interacting protein, and that it further proofs its specificity and reliability on competitive binding experiments involving neutralizing anti-VEGF-A antibodies. Finally, CONAMORE shows the outstanding capability to detect the specific interaction between VEGFR2 and low molecular weight ligands, such as Cyclo-VEGI, a VEGFR2 antagonist cyclo-peptide, that weighs about $2 \mathrm{kDa}$.
\end{abstract}

(c) 2010 Elsevier B.V. All rights reserved.

\section{Introduction}

Protein-protein interactions are the underlying mechanism leading to the activity of every biological system in both physiological and pathological conditions. Since pharmacology and diagnostics are progressing towards specific molecular targets and markers, investigation of protein-protein interactions gained increasing importance in medicine during the last decades. Thus, the development of innovative sensing platforms able to push forward the understanding of thermodynamics and kinetics of these interactions at reasonable costs are still an open and demanding issue (Cheng et al., 2006; Ferrari, 2005).

Protein-protein interactions and their kinetic and thermodynamic parameters can be directly investigated in solution phase or on solid phase assays (Marquette and Blum, 2006; Bergese et al., 2008). Solution phase assays, such as micro-calorimetric (Falconer et al., 2010), are affected by limitations related to the use of large amounts of highly purified proteins (milliliters of pro-

\footnotetext{
* Corresponding author. Tel.: +39 0303715475; fax: +39 0303702448.

** Co-corresponding author. Tel.: +39 0303717312; fax: +39 0303701157

E-mail addresses: mitola@med.unibs.it (S. Mitola), paolo.bergese@ing.unibs.it (P. Bergese).
}

tein solutions at $\mu \mathrm{M}$ concentrations, at least) and to the different conformation that protein can assume in solution with respect to cellular environments (Cooper, 2004). On the contrary, solid phase assays performed on intact cells, cell membrane preparations or with immobilization of the receptors in "cell-like" environments have been used to reveal protein-protein interactions and to study their kinetics. Among these, Enzyme-Linked ImmunoSorbent Assay (ELISA) (Wild, 2005), Surface Plasmon Resonance (SPR) (Rich and Myszka, 2000), radio- or fluorescence-assays (Souriau and Hudson, 2003; Phizicky and Fields, 1995) and Fluorescence Resonance Energy Transfer (FRET) (Wu and Brand, 1994) have to be cited as the most common techniques. Recently, innovative solid phase biosensors have been exploited for the study of protein-protein binding, including electrochemical or electrical immunoassays (Zheng et al., 2005) or micro-mechanical biosensors (Waggoner and Craighead, 2007).

In this communication we spotlight the study of a protein-protein interaction by nanoliter contact angle, named, for this specific application, CONAMORE (CONtact Angle MOlecular REcognition). This new label-free assay is based on the observation that a ligand-receptor interaction supported by a solid phase drives a specific change of the solid-solution interfacial tension (Bergese et al., 2009; Oliviero et al., 2010), that can be straightforwardly detected by sessile drop contact angle measurements 

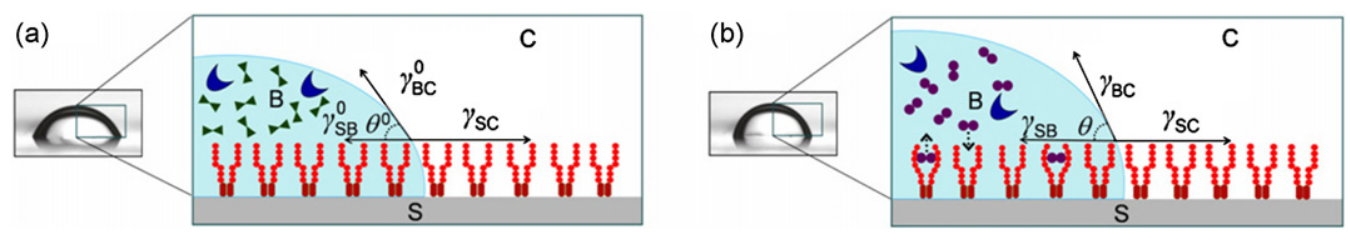

Fig. 1. Schematic of sessile drop CA systems at equilibrium formed by a drop of ligand solution (phase B), a receptor-functionalized surface (phase $S$ ), and a surrounding phase (phase $C$ ); the CA is indicated by $\theta$. Panel (a) represents the unspecific case, where ligands and receptors do not bind; panel (b) represents the specific case, where ligands and receptors bind.

(Fig. 1). In particular, we show that the proof-of-concept we implemented to detect DNA duplex formation (Bergese et al., 2009) can be profitably extended to investigate the more demanding case of the interactions between soluble protein ligands with their surface-immobilized cellular receptors. This application marks down a new path for the contact angle technique as well, that so far has been exclusively deployed to study physisorption and wettability of protein films (see for e.g., Sigal et al., 1998; Rios and Smirnov, 2009).

We investigate the interaction between the tumor-produced pro-angiogenic vascular endothelial growth factor (VEGF-A) at nanomolar concentrations and the surface-immobilized extracellular domain of its endothelial cell receptor VEGFR2, featuring VEGF-A/VEGFR2 binding in the presence of non-interacting proteins, competitive binding experiments and detection of binding of small peptide ligands to VEGFR2. This ligand-receptor system has a fundamental impact in biomedicine, since it promotes angiogenesis, the process of new blood vessel formation from pre-existing ones that plays a key role in human cancer proliferation (Folkman, 1995). Experimental evidences point to the VEGF-A/VEGFR2 system as an important target for the development of anti-angiogenic therapies aimed at inhibiting the tumor growth and the metastatic process (Ferrara et al., 2003). Accordingly, neutralizing anti-VEGF-A antibodies and VEGFR2 inhibitors have shown promising antineoplastic effects in cancer patients (Hurwitz et al., 2004).

CONAMORE results to be very reliable and sensitive. These aspects together with the label-free nature of the technique constitute decisive advantages with respect to ELISA, radio- or fluorescence-assays and electrical or electrochemical immunoassays (Morgan et al., 1996; Lee et al., 2009). On the other hand, the use of minute quantities of ligand solutions - hundreds of nanoliters, potentially reducible to hundreds of picoliters (Taylor et al., 2007) - and the low cost of the instrumentation place CONAMORE in a favorable position to compete with mature labelfree assays such as SPR (Huang et al., 1998) and Isothermal Titration Calorimetry (ITC) (Kim and Kiick, 2007). Beyond these practical advantages, the transduction principle of CONAMORE opens original perspectives in the understanding of thermodynamics and kinetics of ligand-receptor interactions, in the investigation of ligand-induced conformational changes and in the identification/screening of low molecular weight (LMW) ligands, such as peptides and drugs.

\section{Experimental details}

\subsection{Biomolecules and chemicals}

Recombinant human extracellular domain of VEGFR2-Fc (sVEGFR2/Fc) chimeras were from RELIATech GmbH (Braunschweig, Germany). Human recombinant vascular endothelial growth factor-A165 (VEGF-A) was from R\&D Systems (Minneapolis, $\mathrm{MN}$ ) and bovine serum albumin (BSA) from Sigma-Aldrich, Germany.

VEGF-A was dissolved in phosphate buffered saline (PBS, Sigma-Aldrich, Germany), pre-equilibrated with cyclohexane
(Sigma-Aldrich, Germany). Solutions of VEGF-A were also prepared with the addition of $1 \mu \mathrm{M}$ BSA.

Anti-human VEGF-A monoclonal antibody (specific antibody) and anti-human IL-8 monoclonal antibody (irrelevant antibody) (R\&D Systems, Minneapolis, MN, USA) were dissolved at a final concentration of $0.01 \mu \mathrm{g} \mu \mathrm{l}^{-1}$ in a PBS solution containing $100 \mathrm{nM}$ VEGF-A and $1 \mu \mathrm{M}$ BSA.

Cyclo-VEGI (CBO-P11, MW=1998.3 Da, Calbiochem, CA, USA) and VEGF15 (D'Andrea et al., 2005, MW = $1948 \mathrm{Da}$ ) were dissolved in PBS (with the addition of $1 \mu \mathrm{M}$ BSA) in order to obtain a final concentration of $1 \mu \mathrm{M}$.

\subsection{Surface functionalization}

Surface Plasmon Resonance (SPR) chips with the CM3 functionalization (BIAcore Inc., Piscataway, NJ, USA) were employed as substrates for the contact angle measurements.

To this purpose, the CM3 chips were detached from the plastic holder, rinsed with HBS-EP buffer $(10 \mathrm{mM}$ HEPES, pH 7.4, $150 \mathrm{mM} \mathrm{NaCl}, 3 \mathrm{mM}$ EDTA, 0.005\% surfactant P20, BIAcore Inc., Piscataway, NJ, USA) and immersed for $3 \mathrm{~h}$ in $0.2 \mathrm{M}$ N-ethyl-N(3-dimethylaminopropyl)-carbodiimide hydrochloride plus $0.05 \mathrm{M}$ $\mathrm{N}$-hydroxysuccinimide. The surfaces were then washed with HBSEP and incubated with $30 \mu \mathrm{l}$ of sVEGFR2/Fc $(1.87 \mu \mathrm{M}$ in $10 \mathrm{mM}$ sodium acetate, $\mathrm{pH} 3.0$ ) for $2 \mathrm{~h}$ at $25^{\circ} \mathrm{C}$ and $14 \mathrm{~h}$ at $4{ }^{\circ} \mathrm{C}$. After sVEGFR2/Fc immobilization, matrix neutralization was performed with $1.0 \mathrm{M}$ ethanolamine ( $\mathrm{pH} 8.5$ ).

After an accurate HBS-EP wash, the functionalized chips were briefly immersed in $10 \mathrm{mM} \mathrm{NaOH}$, washed with HBS-EP and stored in PBS at $4^{\circ} \mathrm{C}$.

\subsection{Protein and peptides binding measurements with CONAMORE and data analysis}

Sessile drop experiments (Adamson and Gast, 2000) for the determination of the contact angles were carried out at room temperature with a CAM 200 tensiometer (KSV Instruments, Finland) equipped with a Navitar camera and employing cyclohexane as surrounding phase. The employed cyclohexane and the PBS solution were pre-equilibrated in order to avoid solute exchange between the two phases during the experiments.

Sessile drop measurements on the functionalized chips were performed depositing drops of the protein and the peptide solutions with volumes ranging from 150 to 250 nanoliters. The contact angle evolution was monitored for $12 \mathrm{~min}$, acquiring an image every second for the first $3 \mathrm{~min}$ and every $30 \mathrm{~s}$ for the remaining $9 \mathrm{~min}$. The images were analyzed using the KSV CAM Optical Contact Angle and Pendent Drop Surface Tension Software 4.04, fitting the drop profile with the circular or the Young-Laplace algorithms. Since the droplet spreading kinetics indicated that the overall (mechanical and chemical) equilibrium with the substrates was reached about 9 min after the drop deposition (see also Fig. 2 and Section 4), the contact angle value of each drop was taken as the mean value of the last 8 acquired images (from $8.5 \mathrm{~min}$ to 

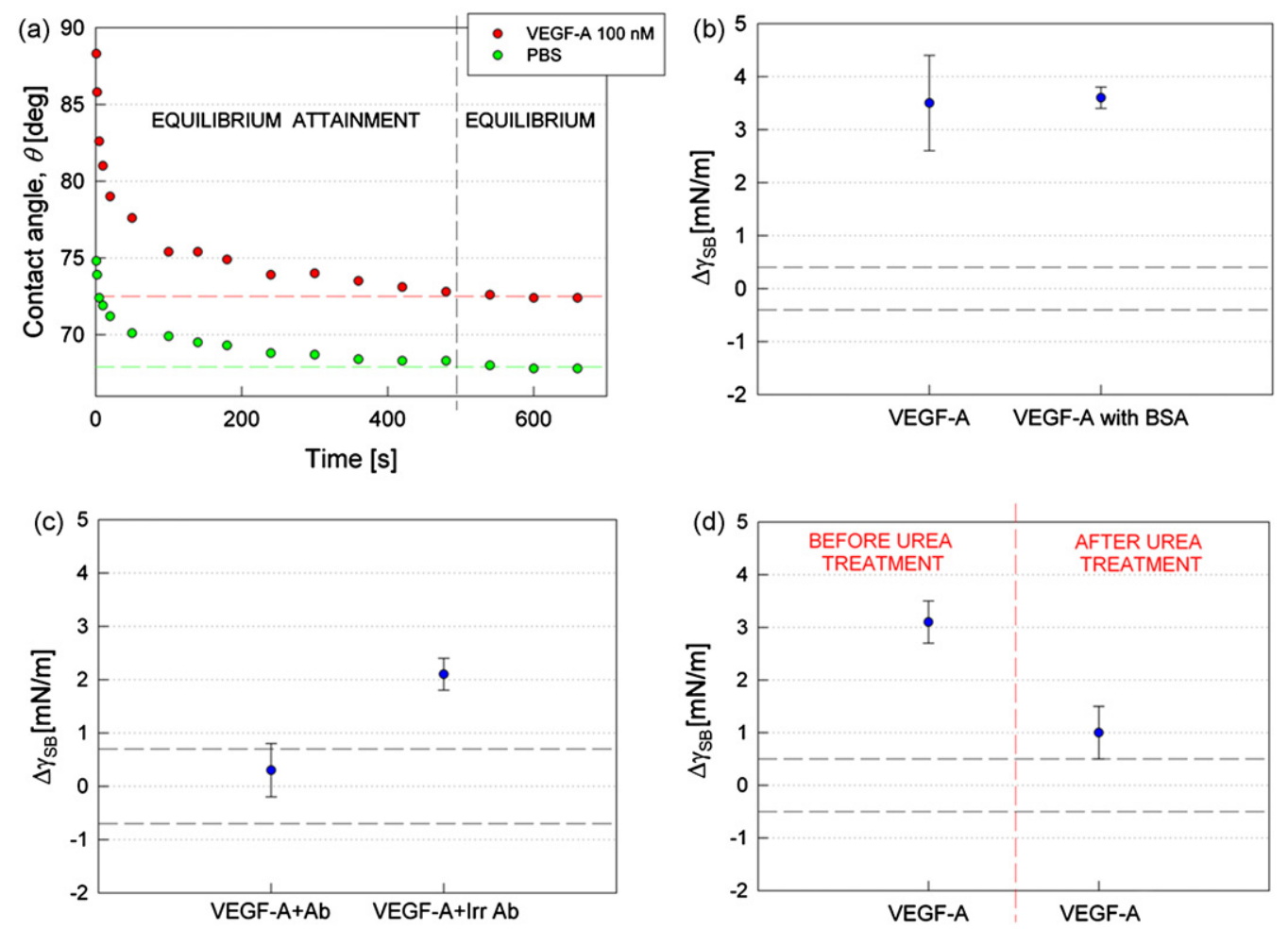

Fig. 2. (a) Spreading kinetics of droplets of the PBS solution of VEGF-A $100 \mathrm{nM}$ (red circles) and of the raw PBS solution (green circles). The variation of the contact angle in the first $9 \mathrm{~min}$ is due to the attainment of the mechanical and chemical equilibrium between the drop, the solid surface and the surrounding phase (cyclohexane). The red and green dotted lines identify the contact angle equilibrium values. Not all the tracked contact angles are reported for clarity reasons. (b) Differential solid-solution interfacial tension, $\Delta \gamma_{S B}$, for a PBS solution of VEGF-A $100 \mathrm{nM}$ with respect to reference (raw) PBS solution (VEGF-A) compared with the $\Delta \gamma_{S B}$ for the same solutions after adding BSA $1.0 \mu \mathrm{M}$ (VEGF-A with BSA). The area of the graph included between the two dotted lines identifies the error associated to the absolute solid-solution interfacial tension of the reference PBS solutions, i.e., the background noise of the signal. (c) $\Delta \gamma_{S B}$ for a PBS solution containing $100 \mathrm{nM}$ VEGF-A, $0.01 \mu \mathrm{g} \mu \mathrm{l}^{-1}$ of a specific anti-VEGF-A antibody and $1.0 \mu \mathrm{M}$ BSA with respect to the same solution without VEGF-A (VEGF-A + Ab) compared with the $\Delta \gamma_{S B}$ for the same solutions but containing an irrelevant antibody in place of the specific one (VEGF-A + Irr-Ab). (d) $\Delta \gamma_{S B}$ for a PBS solution of VEGF-A $100 \mathrm{nM}$ and BSA $1.0 \mu \mathrm{M}$ with respect to reference PBS solution of BSA $1.0 \mu \mathrm{M}$, before and after the treatment of the immobilized receptor VEGFR2 with $6 \mathrm{M}$ urea. (For interpretation of the references to colour in this figure legend, the reader is referred to the web version of the article.).

12 min after the drop deposition). Triplicates of the same drop were deposited in line.

After the deposition of the triplicates of each drop, the chips were reactivated by a brief immersion in $10 \mathrm{mM} \mathrm{NaOH}$ (to remove the bound proteins) and subsequent accurate washings with PBS and Milli-Q water.

The measurements of the interfacial tension between cyclohexane and the protein and peptide solutions were performed through the pendant drop method (Adamson and Gast, 2000).

The values of the contact angles and solution-surrounding phase interfacial tensions were taken as the mean of the three independent replicates and the errors evaluated as the standard deviations of the mean.

Contact angle measurements were also performed on substrates after a treatment in urea in order to unfold the immobilized receptors. The functionalized chips were immersed in a $6 \mathrm{M}$ solution of urea for 30 min and then accurately rinsed in HBS-EP buffer.

\subsection{ELISA}

A 96-well plate was coated for $16 \mathrm{~h}$ at room temperature with $250 \mathrm{ng} / \mathrm{ml}$ of sVEGFR2/Fc in PBS at $100 \mu \mathrm{l} /$ well. When indicated, the plate was incubated in cyclohexane for $5 \mathrm{~min}$ and then washed with PBS before a 3-h blocking step with 1\% BSA. Then, VEGF-A (20 ng/ml dissolved in PBS or in PBS pre-equilibrated with cyclohexane) was added and incubated for $1 \mathrm{~h}$ at $37^{\circ} \mathrm{C}$ followed by $1 \mathrm{~h}$ incubation at room temperature (Ponticelli et al., 2008). An antihuman VEGF monoclonal antibody (R\&D System, Minneapolis, MN) diluted in PBS at $300 \mathrm{ng} / \mathrm{ml}$ was added to the wells and incubated for $1 \mathrm{~h}$ at $37^{\circ} \mathrm{C}$ followed by $1 \mathrm{~h}$ incubation at room temperature. Finally, wells were incubated for $1 \mathrm{~h}$ at room temperature with a secondary donkey anti-mouse horseradish peroxidase-conjugated antibody (Santa Cruz Biotechnology, Santa Cruz, CA, USA).

\section{Theory and calculation}

The equilibrium of a ligand-receptor binding reaction confined at the interface between a solid functionalized with the receptors and a solution supplying the ligands (Bergese et al., 2007) is described by the surface van't Hoff isotherm

$\Delta_{r} G^{0}=-\frac{\Delta \gamma}{\left[\Gamma_{\mathrm{LR}}\right]}-R T \ln K^{\sigma}$

where $\Delta_{r} G^{0}$ is the standard molar Gibbs free energy of the reaction in (free) solution, $\Delta \gamma$ is the variation of the solid-solution interfacial tension upon binding, $\left[\Gamma_{\mathrm{LR}}\right]$ is the equilibrium surface density of the ligand-receptor complexes, $K^{\sigma}$ is the surface equilibrium constant (or binding affinity), ${ }^{1}$ and $R$ and $T$ are the ideal gas constant and the absolute temperature, respectively. Eq. (1) quantifies how a part of the Gibbs free energy of the reaction is employed to accommodate binding on the surface, driving the change of the solid-solution interfacial tension $\Delta \gamma$.

$\Delta \gamma$ can be directly evaluated by sessile drop contact angle experiments. When a droplet is placed onto a solid surface it

\footnotetext{
${ }^{1}$ For further details on the difference between $K^{\sigma}$ and the equilibrium constant in free solution, please refer to Oliviero et al. (2010).
} 
Table 1

Optical density values for the ELISA experiments. The table shows the absorbance values registered on immobilized VEGFR2 when incubated with a PBS buffered solution, a PBS buffered solution of VEGF-A $100 \mathrm{nM}$, or a solution of VEGF-A $100 \mathrm{nM}$ in PBS pre-equilibrated with cyclohexane (VEGF-A*) before and after the exposure of the immobilized receptors to cyclohexane.

\begin{tabular}{lll}
\hline & $\begin{array}{l}\text { Before VEGFR2 exposure } \\
\text { to cyclohexane }\end{array}$ & $\begin{array}{l}\text { After VEGFR2 exposure } \\
\text { to cyclohexane }\end{array}$ \\
\hline Vehicle & 0.424 & 0.432 \\
VEGF-A & 0.918 & 0.869 \\
VEGF-A & 0.868 & 0.875 \\
\hline
\end{tabular}

reaches the equilibrium with the surface and the surroundings at the contact line at which drop, surface and surroundings meet, identifying a definite contact angle $\theta$ (Young, 1805 and Fig. 1). $\theta$ is linked to the interfacial tensions by the Young-Dupré equation (Adamson and Gast, 2000). CONAMORE roots on this physicochemical phenomenon and can be illustrated with the help of Fig. 1. Here the surface, $S$, is functionalized with a receptor and the droplet, $B$, is a solution of unspecific or specific ligands for the immobilized receptor (panel (a) or (b), respectively); $C$ is the surrounding phase. The specific binding reaction featured by system (b) gives a specific contribution to the solid-solution interfacial tension, $\gamma_{S B}$, that is missed in the interfacial tension of the unspecific system (a), $\gamma_{S B}^{0}$, taken as reference. Thus, as suggested by Eq. (1), specific binding is associated to a change (differential) of the solid-solution interfacial tensions $\Delta \gamma_{S B}=\gamma_{S B}-\gamma_{S B}^{0}$. In other words, $\gamma_{S B}$ can be regarded as the transduction signal of the specific binding event. An analogous concept holds if pure buffer is considered instead of an unspecific ligand solution.

As mentioned above, interfacial tensions are related to contact angles by the Young-Dupré equation, and it can be shown that for the system under consideration the following equation holds (Bergese et al., 2009):

$\Delta \gamma_{S B}=\gamma_{S B}-\gamma_{S B}^{0}=\gamma_{B C}^{0} \cos \theta^{0}-\gamma_{B C} \cos \theta$

where $\theta^{0}$ and $\theta$ are the contact angles of the unspecific and of the specific systems, respectively, and, analogously, $\gamma_{B C}^{0}$ and $\gamma_{B C}$ are the solution-surrounding phase interfacial tensions of the unspecific and of the specific systems, respectively. Eq. (2) allows to directly determine the transduction signal $\Delta \gamma_{S B}$ by measuring $\theta^{0}$ and $\theta$ by sessile drop contact angle experiments, provided that $\gamma_{B C}^{0}$ and $\gamma_{B C}$ were previously determined (for example by pendant drop experiments, see Section 2). Eq. (2) also indicates that in the particular case in which $\gamma_{B C}^{0} \cong \gamma_{B C}$ the contact angles difference is biunivocally related to $\Delta \gamma_{S B}$, and thus directly probes the specific binding.

\section{Results}

\subsection{Receptor surface functionality}

CONAMORE experiments were performed with cyclohexane as surrounding phase in order to avoid evaporation of the nanoliter drops and to enhance the solution contact angles with the surface. Measurement of water solution contact angle under organic solvents is a reliable method to evaluate the energetics of protein binding to different surfaces (Sigal et al., 1998). Moreover, from a theoretical perspective, proteins in non-polar organic solvents preserve their functionality as, in principle, they do not unfold because of the increased stability of their non-polar groups in such environments (Pace et al., 2004). However, to be on the safe side, we designed and performed ELISA tests to experimentally check the hypothesis that cyclohexane does not affect the binding capacity of VEGFR2 and of its ligand VEGF-A.
The results, reported in Table 1, fully confirmed this hypothesis. In particular, the VEGF-A/VEGFR2 complex is formed after the exposure of the immobilized VEGFR2 to cyclohexane, also when VEGF-A is dissolved in a PBS solution pre-equilibrated with cyclohexane.

\subsection{Ligand-receptor binding experiments}

The first experiment was the detection of VEGF-A/VEGFR2 specific binding. To this purpose we measured the differential solid-liquid interfacial tension, $\Delta \gamma_{S B}$, between a PBS solution of VEGF-A and the raw PBS solution (taken as reference). The concentration of VEGF-A was fixed at $100 \mathrm{nM}$ in order to have a large excess of ligand in the deposited drop when compared to the $K_{\mathrm{d}}$ value for the VEGF-A/VEGFR2 interaction, approximately equal to $30 \mathrm{nM}$ (Huang et al., 1998).

Fig. 2 (panel a) shows the evolution with time of the contact angles of the VEGF-A and PBS (reference) drops. The spreading kinetics show that the mechanical and chemical equilibrium of the drops with the surface and the surrounding phase (cyclohexane) is reached about $9 \mathrm{~min}$ after deposition. By substituting into Eq. (2) the equilibrium values of the contact angles, $\theta^{0}=67.5 \pm 0.3^{\circ}$ and $\theta=73.5 \pm 1.3^{\circ}$, and of the solution-cyclohexane interfacial tensions, $\Delta \gamma_{B C}^{0}=35.2 \pm 0.7 \mathrm{mN} \mathrm{m}^{-1}$ and $\gamma_{B C}=35.2 \pm 0.7 \mathrm{mN} \mathrm{m}^{-1}$, we obtain $\Delta \gamma_{S B}=3.5 \pm 0.9 \mathrm{mN} \mathrm{m}^{-1}$. This value is a significant transduction signal, giving the first, solid proof of the possibility to probe the interaction between VEGF-A and VEGFR2 by CONAMORE.

Next we assessed the capability of CONAMORE to probe the VEGF-A/VEGFR2 interaction also in the presence of a large molar excess of proteins that might interfere with the detection of the complex formation. To this purpose, we chose BSA (Bovine Serum Albumin) as a demonstrative non-specific interactor, since this protein is used as a carrier in most of the routine techniques aimed at ligand-receptor binding studies. On this basis, we measured $\Delta \gamma_{S B}$ of a PBS solution of VEGF-A $100 \mathrm{nM}$ and BSA $1.0 \mu \mathrm{M}$ with respect to a reference PBS solution of BSA $1.0 \mu \mathrm{M}$; we obtained $\Delta \gamma_{S B}=3.6 \pm 0.2 \mathrm{mN} \mathrm{m}^{-1}$. As shown in Fig. 2 (panel b) this value is consistent with the $\Delta \gamma_{S B}$ measured for the BSA free solutions, demonstrating that (i) the high concentration of BSA (ten-folds the concentration of VEGF-A) does not affect the interaction between VEGF-A and VEGFR2 and that (ii) CONAMORE is extremely reliable and specific. In view of these observations and of the lower experimental uncertainty, all the next experiments were performed by adding to the buffer solution $1.0 \mu \mathrm{M}$ BSA as a carrier; this solution will be hereafter referred as PBS/BSA solution.

The specificity and reliability of CONAMORE was further tested through a competition experiment in which a specific neutralizing anti-VEGF-A antibody prevents the interaction between VEGF-A and VEGFR2. As shown in Fig. 2 (panel c) $\Delta \gamma_{S B}$ for a PBS/BSA solution containing $100 \mathrm{nM}$ of VEGF-A plus $0.01 \mu \mathrm{g} \mu \mathrm{l}^{-1}$ of antiVEGF-A antibody ( $\mathrm{Ab}$ ) with respect to the reference PBS/BSA solution is equal to $0.3 \pm 0.5 \mathrm{mN} \mathrm{m}^{-1}$. This means that CONAMORE, as expected, indicates that the antibody interacts with VEGF-A and prevent it from binding VEGFR2. Instead, when the specific antiVEGF-A antibody is replaced by an irrelevant antibody (Irr-Ab) that does not interfere with the VEGF-A/VEGFR2 binding, $\Delta \gamma_{S B}$ comes back to $2.1 \pm 0.3 \mathrm{mN} \mathrm{m}^{-1}$, which is a value comparable with the previously measured $\Delta \gamma_{S B}$ of the VEGF-A/VEGFR2 binding.

Receptor interaction strongly depends on a proper conformational structure of the receptor that allows the recognition of the ligand by specific binding site(s) on the receptor protein surface. As a proof of the reliability of the CONAMORE signal due to the interaction between VEGF-A and VEGFR2, we measured $\Delta \gamma_{S B}$ of a PBS/BSA solution of VEGF-A $100 \mathrm{nM}$ with respect to the reference PBS/BSA solution onto immobilized VEGFR2 before and after exposure of immobilized VEGFR2 to urea $6 \mathrm{M}$, that completely unfolds 


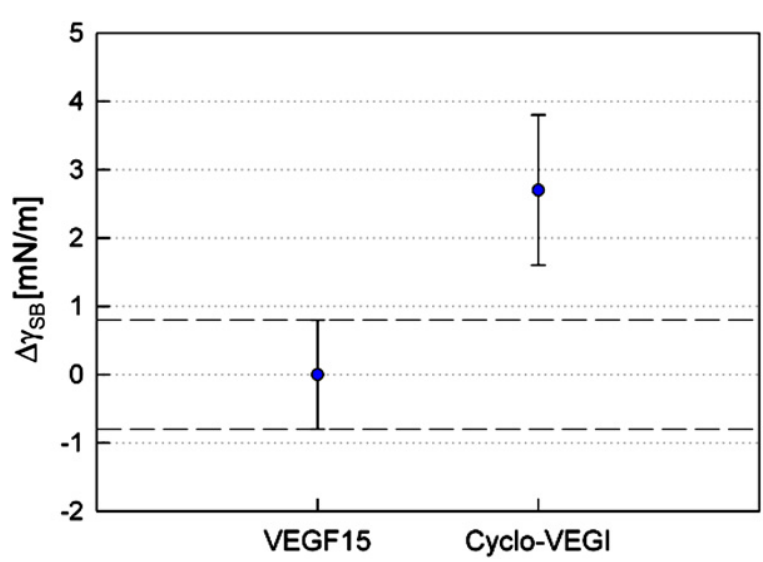

Fig. 3. (a) Differential solid-solution interfacial tension, $\Delta \gamma_{S B}$, for a PBS solution of Cyclo-VEGI $1 \mu \mathrm{M}$ with respect to a PBS solution of VEGF15 $1 \mu \mathrm{M}$ (both the solutions also contain BSA $1.0 \mu \mathrm{M}$ ). The area of the graph included between the two dotted lines identifies the error associated to the absolute solid-solution interfacial tension of the (reference) VEGF15 solution, i.e., the background noise of the signal.

the immobilized protein (Scholtz et al., 1995). The results, reported in Fig. 2 (panel d) show that, with the folded VEGFR2, VEGF-A binding drives a $\Delta \gamma_{S B}$ equal to $3.0 \pm 0.4 \mathrm{mN} \mathrm{m}^{-1}$, that is significantly different from the one measured with the unfolded VEGFR2, $\Delta \gamma_{S B}=1.0 \pm 0.5 \mathrm{mN} \mathrm{m}^{-1}$. This indicates a dramatic suppression of the specific interaction between VEGF-A and VEGFR2 following the disruption of the conformational structure of the receptor. On the other hand, the binding $\Delta \gamma_{S B}$ from this experiment is fairly consistent with the ones obtained in the previous experiments, bringing an additional proof of the repeatability of CONAMORE measurements.

CONAMORE was finally tested for its ability to detect the specific interaction of VEGFR2 with low molecular weight (LMW) ligands. To this purpose we used, as a model ligand, the peptide CycloVEGI, a well-known VEGFR2 antagonist (Zilberberg et al., 2003) that weights $1998 \mathrm{Da}$. In order to eliminate the possible contribution of non-specific adsorption that may occur when employing LMW molecules on biopolymer functionalized surfaces (Serizawa et al., 2007), the LMW peptide VEGF15 was used as the negative control (D'Andrea et al., 2005). $\Delta \gamma_{S B}$ for a PBS/BSA solution of CycloVEGI $1 \mu \mathrm{M}$ with respect to a reference PBS/BSA solution of VEGF15 $1 \mu \mathrm{M}$ resulted $2.7 \pm 1.1 \mathrm{mN} \mathrm{m}^{-1}$ (Fig. 3 ), confirming the auspicated performances of CONAMORE with LMW species.

\section{Conclusions}

The inedited and successful application of CONAMORE to the recognition of interactions between cell membrane receptors and angiogenic growth factors was described. In particular the interaction between the immobilized VEGFR2 receptor and nanomolar concentrations of its specific ligand VEGF-A was detectable with a consistent transduction signal in the presence of a ten-fold molar excess of an unrelated protein $(1.0 \mu \mathrm{M}$ BSA $)$ or of irrelevant immunoglobulins and was distinguished from the non-specific interactions occurring after denaturation of the receptors. The extraordinary specificity, reliability and repeatability of the technique were confirmed by a competition experiment, where CONAMORE revealed the VEGF-A/VEGFR interaction suppression by a neutralizing anti-VEGF-A antibody. Finally, the detection of the interaction between Cyclo-VEGI, a $2 \mathrm{kDa}$ cyclo-peptide, and VEGFR2 demonstrates the technique capability to evaluate the binding of LMW molecules to surface-immobilized proteins.

These experiments spotlight the role that CONAMORE can play in the study of protein-protein interactions, being a label-free technique with an easier access and a lower cost in comparison with established methods such as SPR or Quartz Crystal Microbalances (QCM). Furthermore, the recent development of automated picoliter instruments candidates CONAMORE as a decisive player in applications where small volumes of analyte and/or multiplexed operation are mandatory. Finally, the direct transduction of the energy of the interactions opens new perspectives, not only in the widening of the understanding of surface confined ligand-receptor interactions, but also in the study of interactions that induce conformational changes of the proteins and in the identification of low molecular weight receptor agonists and antagonists with potential therapeutic implications.

\section{Acknowledgements}

This work was supported by Fondazione Cariplo (grant no. 2008.2198), by the Italian Ministry of Education, University and Scientific Research (grant no. PRIN 2008 JWKYXB: "Phononic crystals and near field spectroscopy applied to femtosecond time-resolved optical experiments for studying the dynamics of the biomolecular interactions among angiogenic factors") and by AIRC to SM and MP (grant no. MFAG9161).

\section{References}

Adamson, A., Gast, A.P., 2000. Physical Chemistry of Surfaces, 6th ed. Wiley, New York, pp. 48-100, 390-430 and 599-684.

Bergese, P., Cretich, M., Oldani, C., Oliviero, G., Di Carlo, G., Depero, L.E., Chiari, M., 2008. Curr. Med. Chem. 15, 1706-1719.

Bergese, P., Oliviero, G., Alessandri, I., Depero, L.E., 2007. J. Colloid Interface Sci. 316 , 1017-1022.

Bergese, P., Oliviero, G., Colombo, I., Depero, L.E., 2009. Langmuir 25, 4271-4273.

Cheng, M.M., Cuda, G., Bunimovich, Y.L., Gaspari, M., Heath, J.R., Hill, H.D., Mirkin, C.A., Nijdam, A.J., Terracciano, R., Thundat, T., Ferrari, M., 2006. Curr. Opin. Chem. Biol. 10, 11.

Cooper, M., 2004. J. Mol. Recognit. 17, 286.

D’Andrea, L.D., Iaccarino, G., Fattorusso, R., Sorriento, D., Carannante, C., Papasso, D., Trimarco, B., Pedone, C., 2005. Proc. Natl. Acad. Sci. USA 102 (40), 14215.

Falconer, R.J., Penkova, A., Jelesarov, I., Collins, B.M., 2010. J. Mol. Recognit., doi:10.1002/jmr.1025.

Ferrara, N., Gerber, H.P., LeCouter, J., 2003. Nat. Med. 9, 669.

Ferrari, M., 2005. Nat. Rev. Cancer 5, 161.

Folkman, J., 1995. Nat. Med. 1, 27.

Huang, X., Gottstein, C., Brekken, R.A., Thorpe, P.E., 1998. Biochem. Biophys. Res. Commun. 252, 643.

Hurwitz, H., Fehrenbacher, L., Novotny, W., Cartwright, T., Hainsworth, J., Heim, W., Berlin, J., Baron, A., Griffing, S., Holmgren, E., Ferrara, N., Fyfe, G., Rogers, B., Ross, R., Kabbinavar, F., 2004. New Engl. J. Med. 350, 233.

Kim, S.H., Kiick, K.L., 2007. Peptides 28, 2125.

Lee, H.-S., Kim, K.S., Kim, C.-J., Hahn, S., Jo, M.H., 2009. Biosens. Bioelectron. 24, 1801. Marquette, C.A., Blum, L.J., 2006. Biosens. Bioelectron. 21, 1424.

Morgan, C.L., Newman, D.J., Price, C.P., 1996. Clin. Chem. 42, 193

Oliviero, G., Federici, S., Colombi, P., Bergese, P., Published in early view 2010. J. Mol. Recognit., doi:10.1002/jmr.1019.

Pace, C.N., Treviño, S., Prabhakaran, E., Scholtz, J.M., 2004. Philos. Trans. R. Soc. London Ser. B 359, 1225.

Phizicky, E.M., Fields, S., 1995. Microbiol. Rev. 59, 94.

Ponticelli, S., Marasco, D., Tarallo, V., Albuquerque, R.J.C., Mitola, S., Takeda, A. Stassen, J.M., Presta, M., Ambati, J., Ruvo, M., De Falco, S., 2008. J. Biol. Chem. 283, 34250.

Rich, R.L., Myszka, D.G., 2000. Curr. Opin. Biotechnol. 11, 54.

Rios, F., Smirnov, S., 2009. ACS Appl. Mater. Interfaces 1, 768.

Scholtz, J.M., Barrick, D., York, E.J., Stewart, J.M., Baldwin, R.L., 1995. Proc. Natl. Acad. Sci. USA 92 (1), 185.

Serizawa, T., Sawada, T., Matsuno, H., 2007. Langmuir 23, 11127.

Sigal, G.B., Mrksich, S.G., Whitesides, G.M., 1998. J. Am. Chem. Soc. 120, 3464

Souriau, C., Hudson, P.J., 2003. Expert Opin. Biol. Ther. 3, 305.

Taylor, M., Urquhart, A.J., Zelzer, M., Davies, M.C., Alexander, M.R.P., 2007. Langmuir $23,6875$.

Waggoner, P.S., Craighead, H.G., 2007. Lab. Chip 7, 1238.

Wild, D., 2005. The Immunoassay Handbook, 3rd ed. Elsevier, Heidelberg.

Wu, P., Brand, L., 1994. Anal. Biochem. 218, 1.

Young, T., 1805. Philos. Trans. R. Soc. London 95, 65, This essay has been digitized and is available at www.google.com/books.

Zheng, G., Patolsky, F., Cui, Y., Wang, W.U., Lieber, C.M., 2005. Nat. Biotechnol. 23, 1294.

Zilberberg, L., Shinkaruk, S., Lequin, O., Rousseau, B., Hagedorn, M., Costa, F., Caronzolo, D., Balke, M., Canron, X., Convert, O., La, G., Gionnet, K., Goncalves, M., Bayle, M., Bello, L., Chassaing, G., Deleris, G., Bikfalvi, A., 2003. J. Biol. Chem. 278 (37), 35564. 